
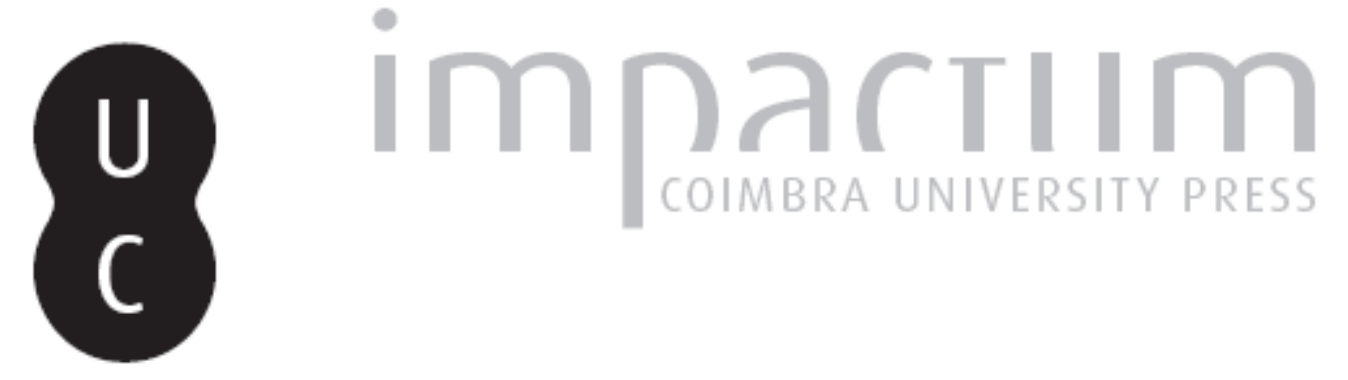

\title{
Subsídios para a carta arqueológica do período romano na área de Conímbriga Autor(es): Pessoa, Miguel
}

Publicado por: Imprensa da Universidade de Coimbra

URL persistente:

URI:http://hdl.handle.net/10316.2/45610

DOI:

DOI:https://dx.doi.org/10.14195/1647-8657_25_4

Accessed : $\quad$ 26-Apr-2023 13:04:54

A navegação consulta e descarregamento dos títulos inseridos nas Bibliotecas Digitais UC Digitalis, UC Pombalina e UC Impactum, pressupõem a aceitação plena e sem reservas dos Termos e Condições de Uso destas Bibliotecas Digitais, disponíveis em https://digitalis.uc.pt/pt-pt/termos.

Conforme exposto nos referidos Termos e Condições de Uso, o descarregamento de títulos de acesso restrito requer uma licença válida de autorização devendo o utilizador aceder ao(s) documento(s) a partir de um endereço de IP da instituição detentora da supramencionada licença.

Ao utilizador é apenas permitido o descarregamento para uso pessoal, pelo que o emprego do(s) título(s) descarregado(s) para outro fim, designadamente comercial, carece de autorização do respetivo autor ou editor da obra.

Na medida em que todas as obras da UC Digitalis se encontram protegidas pelo Código do Direito de Autor e Direitos Conexos e demais legislação aplicável, toda a cópia, parcial ou total, deste documento, nos casos em que é legalmente admitida, deverá conter ou fazer-se acompanhar por este aviso.

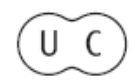


FACULDADE DE LETRAS

INSTITUTO DE ARQUEOLOGIA

CONIMBRIGA

$V O L U M E X X V$

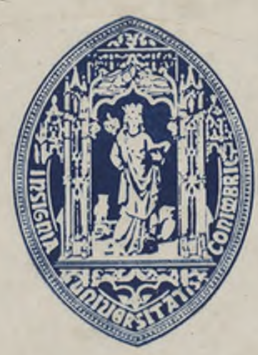

UNIVERSIDADE DE COIMBRA

1986 
Miguel Pesson

Conservador do Museu Monográfico de Conimbriga

SUBSÍDIOS PARA A CARTA ARQUEOLÓGICA DO PERÍODO

ROMANO NA ÁREA DE CONIMBRIGA

«Conimbriga», XXY (1986), p. 53-73

Resumo: $\quad$ O autor fornece pistas para o estudo da carta arqueológica na área de Conimbriga, assinalando mais de duas dezenas de locais de época romana, entre os quais algumas «villae» no concelho de Condeixa-a-Nova.

Résumí: L'auteur donne quelques éléments pour l'étude de la carte archéologique dans l'environnement de Conimbriga, en signalant plus de deux dizaines de sites d'époque romaine, permi lesquels quelques «villae» de l'actuelle commune de Condeixa-a-Nova. 
(Página deixada propositadamente em branco) 


\section{SUBSÍDIOS PARA A CARTA ARQUEOLÓGICA DO PERÍODO ROMANO NA ÁREA DE CONIMBRIGA}

\section{Introdução}

Exceptuando, obviamente, a abundante bibliografía sobre Conimbriga, são escassas e pouco seguras as informações sobre os vestígios de época romana no concelho de Condeixa. A documentação referente às «Memórias Paroquiais» de 1758 íl) é uma fonte escrita que poderá fornecer alguns dados com interesse. Os Livros de Matrizes Prediais Rústicas, manuscritos do princípio do século, são outra fonte de informações por recolher. Apesar de consultadas fotografias aéreas da região e de realizada uma preliminar análise toponímica por freguesias, foi do inquérito à população que resultou a localização de novos sítios arqueológicos e de achados avulsos romanos. Se, nalguns casos, a ausência de vestígios está intimamente relacionada com a inospitalidade dos locais entre a zona sul e sudoeste do concelho, noutros, porém, ela deve-se à simples razão de o nosso esforço não ter ainda incidido nessas áreas.

A elaboração do mapa de ocupação e a deteç̧ão dos achados avulsos levou-nos a sentir a necessidade de procurar registar o maior número possível de dados que permitam facilmente realizar futuras visitas. Daí o preenchimento de uma ficha que deverá ser aperfeiçoada para todos os sítios.

(!) Foram já consultadas as «Memórias Paroquiais» que dizem respeito às freguesias de Belide, Bendafé, Condeixa-a-Nova, Condeixa-a-Velha e Rabaçal (Arquivo Nacional da Torre do Tombo, Lisboa). 
Torna-se imprescindível o levantamento em planta de pormenor dos locais dos achados pois se ela não for feita corre-se o risco de perder informações importantes para o estudo local da ocupação humana na época romana.

\section{Carta arqueológica}

Cada estação é designada pelo microtopónimo, seguida do nome da localidade mais próxima e do nome da freguesia em que se situa.

Em a) indicamos as coordenadas militares e a folha da Carta Militar na escala 1:25.000. Em b) fazemos uma descrição geomorfológica sumária. Em c) indicamos as condições da descoberta e os achados feitos. Em d) sugerimos o tipo de estação, villa ou casal. Em e) damos bibliografia, quando existe.

1 - Pedrógãos, Casével, Ega.

a) Coordenadas Militares: 163,$55 ; 350,9$; Folha 240 .

b) $\mathrm{O}$ terreno apresenta uma camada de areão com abundantes calhaus rolados, sobreposto a uma camada argilosa, mais impermeável, o que possibilita a retenção de alguma água. $\mathrm{O}$ terreno está plantado de vinha e à volta abunda o pinheiro, a oliveira, árvores de fruto e diversas culturas de sequeiro. Deste ponto alto observa-se a Norte a planura de Belide/Ega cujos terrenos de aluvião estão sujeitos a inundações *.

c) Achados superficiais recolhidos em batida de campo. Foram seleccionadas amostras de «tegula» e cerâmica comum que deram entrada no Museu de Conimbriga em 1983. O denário dos finais do séc. $\mathrm{n}$ e início do i a.C.

* As descrições geomorfológicas foram orientadas pelo geólogo António F. Tavares, do Museu Monográfico de Conimbriga. 
descoberto nesta zona poderá estar ligado ao sítio agora identificado (Est. III, 2).

Fomos acompanhados ao local pelo Sr. Manuel Lázaro de Belide, empregado bancário. A propriedade pertence ao Sr. Manuel Pinão, guarda-rios de Casével.

d) «Villa»?

e) Isabel Pereira, Miguel Pessoa, Moedas Romanas de Condeixa. Achados dispersos, «Filatelia-Numismática», 5, Lisboa, 1981, p. 28-30.

2 - Areias, Venda da Luisa, Anobra.

d) Coordenadas Militares: 165,5; 352,15; Folha 240.

b) Terra de cultivo, solta, leve, um pouco arenosa mas fértil e com água. Assenta numa plataforma que se estende em pendor muito suave até às várzeas da Ribeira de Anobra. Os campos de cultivo alternam com pequenos pinhais.

c) Achados superficiais recolhidos em batida de terreno: «dolium» (Est. IV), mó dormente em grés, fragmentos de «tegula», «imbrex», tijolos de coluna, peso de tear e cerâmica comum. Deram entrada no Museu de Conimbriga em 1983. Os vestígios encontram-se dispersos por uma área de mais de mil metros quadrados.

Fomos acompanhados ao local pela professora da escola primária, Catarina Maurício.

A propriedade pertence ao Sr. Armando Vaz, da Venda da Luisa.

d) «Villa»?

3-«Castro do Outeiro», Sebal.

a) Folha 240 .

c) Não pôde ser determinada a localização exacta dos achados referidos na monografia de Condeixa citada em e).

e) A. Santos Conceição, Condeixa-a-N ova, Coimbra, 1941, p. 219. 
4 - Moira/Fonte da Moira, Sebal.

a) Coordenadas Militares: 166,15; 349,7; Folha 240.

b) Campos planos com terra barrenta humosa e funda de água abundante.

Cultiva-se vinha, um pouco olival e uma ou outra árvore de fruto.

c) Os vestígios são muito dispersos e espalham-se por uma área de meio hectar.

Os achados superficiais foram recolhidos em batida de terreno e deram entrada no museu em 1983. Trata-se de fragmentos de «tegulae», «imbrices» e pesos de tear.

Fomos acompanhados ao local pelo Sr. José Pinheiro Marques, de S. Fipo, de 41 anos de idade, funcionário dos Caminhos de Ferro (CP).

d) Casal?

5 - Barrios de Baixo, Ega.

a) Coordenadas Militares: 166,15; 349,25; Folha 240.

b) Terra de cultivo quase plana, funda, barrenta e humosa com água entre pinhais e alguns carvalhos, culturas da vinha e hortícolas, algumas oliveiras e poucas árvores de fruto.

c) Achados superficiais recolhidos em batida de campo. Os vestígios são muito abundantes, por vezes muito concentrados e espalham-se por uma área não inferior a meio hectar. Detectaram-se fragmentos de calcário de Porto de Mós e mós manuais em grés grosseiro. Foram recolhidos fragmentos de «tegulae», «imbrices», pesos de tear, tijolos segmentares de coluna e tijoleiras que deram entrada no Museu de Conimbriga em 1983. Um fundo de ânfora, um bordo de «dolium» e um fragmento de vaso de sigillata hispânica (Drag. 15/17, séc. i d.C. ou 1. ${ }^{\text {a }}$ metade do séc. ii d.C. pela boa qualidade de fabrico) foram aqui recolhidos nos anos 60 pelo Sr. João Pimentel das Neves, de Condeixa. 
Fomos acompanhados ao local pelo Sr. José Pinheiro Marques, de S. Fipo.

d) «Villa»?

c) Até que ponto terá esta descoberta a ver com a referência que faz Pinho Leal «...às moedas romanas $\mathrm{e}$ ruínas de grandes edifícios...» quando fala de Sebal Grande, transcrita no «Boletim da Real Associação dos Architectos Civis e Archeologos Portugueses», 9, 4. ${ }^{\text {a }}$ Série, Lisboa, 1903, p. 39 e referida por Santos Conceição na Monografia de Condeixa, editada em 1941, p. $209^{2}$.

6-Moroiços, S. Fipo, Ega.

d) Coordenadas Militares: 167,3; 348,65; Folha 250.

b) Terra funda, barrenta, vinha e culturas hortícolas, cereal e oliveira.

c) Os vestígios espalham-se por mais de cinco mil metros quadrados.

As amostras recolhidas em batida de terreno (mosaico polícromo, fragmentos de «tegula», «imbrex» e cerâmica comum) deram entrada no museu em Maio de 1983.

O terreno foi surribado em 1983 tendo-se verificado a destruição de estruturas e pavimento de mosaico. Esta propriedade pertence a José Pinheiro Marques. Fomos acompanhados ao local pelo Sr. Fernando Cera Areeiro, de S. Fipo. Tínhamos sido alertados algum tempo antes para este facto pelo Sr. Luís Simões Pato, de S. Fipo, sargento aposentado da Marinha.

d) «Villa».

7 - Ponte da Sancha, Condeixa-a-Velha.

a) Coordenadas Militares: 168,45; 347,75; Folha 251.

c) d) Ponte romana conservando vestígios de alicerces dos três arcos e arranque do arco de um deles (alvenaria e silharia exterior) a 100 metros a juzante da Fonte da Sancha, 
na margem direita do Rio dos Mouros, ao fundo do vale, depois do lavadouro e fonte da zona mais antiga de Condeixa-a-Velha.

e) Augusto dos Santos Conceição, Condeixa- $a-N$ ova, Coimbra, 1941, p. 261.

8 - Selão, Sobreiro, Sebal.

a) Coordenadas Militares: 167,35; 351,9; Folha 240.

b) Várzea da Ribeira de Cernache, de terrenos barrentos plantados de cereais, culturas hortícolas, vinha, olival e pinhal.

c) Achado duma armela de sítula dos inícios do séc. m, realizado no decurso de trabalhos agrícolas.

Propriedade de Maria Emilia Bicho, de 79 anos, do Sobreiro.

d) Casal ?

9 - Canto, Quinta da Lapa, Serrado dos Pelomes, Condeixa

a) Coordenadas Militares: 168,7; 349,5; Folha 251.

b) Plataforma intermédia dos tufos de Condeixa dum lado e outro da Ribeira de Condeixa.

c) CANTO: Largo Rodrigo da Fonseca Magalhães, traseira da habitação n. ${ }^{\circ}$ 15. As obras realizadas nos anos 30 revelaram a existência de tijolos segmentares de coluna e de pavimento de «opus signinum».

QUINTA DA LAPA: foi detectado pavimento de «opus signinum» no decurso de trabalhos agrícolas nos anos 60.

SERRADO DOS PELOMES: a abertura de alicerces para uma casa de habitação provocou a descoberta de tijolos segmentares de columa no ano de 1984.

Testemunho oral do Sr. Álvaro Pedro Augusto, de 79 anos, de Condeixa. O último testemunho é do Sr. João Pimentel das Neves, de 69 anos, de Condeixa.

d) «Villa»? 
10 - Capela, Eira Peclrinha, Condeixa-a-Velha.

d) Coordenadas Militares: 170,3; 349,75; Folha 251.

b) $\mathrm{O}$ adro da capela e terrenos adjacentes assentam no rebordo duma plataforma dos tufos calcários de Condeixa.

c) Os vestígios foram detectados durante os trabalhos de alargamento do adro e restauro da capela efectuados em 1937.

Foram então vistos não só tijolos segmentares de coluna mas também pavimento de «opus signinum».

d) «Villa»?

e) Vergilio Correia, A. Nogueira Gonçalves, Inventário Artístico de Portugal, Distrito de Coimbra, 4, Lisboa, 1953, p. 83 .

11 - Revolta Seca, Avessada, Condeixa-a-Velha.

a) Coordenadas Militares: 170,9; 349,1; Folha 251.

ç) O local fica situado nos campos da Ribeira de Alcabideque, no sopé da colina de Avessada, junto à estrada alcatroada de Condeixa a Alcabideque, em terrenos plantados de oliveiras, cereais e culturas hortícolas.

c) Achados superficiais, recolhidos em batida de terreno, pouco numerosos, onde se salientam alguns fragmentos de «tegula» que deram entrada no museu, em 1983. Fomos informados de que, na década de 50, fora aí descoberto um pavimento de mosaico. Não foi possível confirmar o sucedido.

As informações foram-nos transmitidas pelo Sr. José Alves, agricultor reformado, de 91 anos de idade, residente em Alcabideque.

O proprietário do terreno é o Sr. Manuel Miranda Vinagre, da mesma localidade.

d) «Villa»? 
12_Vaiada, Condeixa-a-Velha.

a) Coordenadas Militares: 169,95; 348,65; Folha 251.

b) Entrada poente da aldeia da Vaiada.

c) Achado casual de um apito romano ocorrido durante a abertura de alicerces para uma casa de habitação em 1960, a cerca de $80 \mathrm{~cm}$ de profundidade (Est. Ill, 1).

Este instrumento sonoro de prata, de silvo estridente, tem a forma de elmo militar e está implantado em mesa no aro do anel (diâmetro $20 \mathrm{~mm}$ ). O elmo tem $28 \mathrm{~mm}$ de altura e $9 \mathrm{~mm}$ de espessura.

Pertence ao Sr. Augusto Geada, de Condeixa, que está disposto a vendê-lo ao Museu de Conimbriga.

13 - Carrascal, Serra da Ponte, Condeixa-a-Velha.

a) Coordenadas Militares: 171,25; 348,25; Folha 251 .

b) $\mathrm{O}$ local fica situado numa pequena plataforma que interrompe o pendor da encosta oriental da Colina da Ponta (terrenos Liássicos), plantada de oliveira, pinheiro e ciprestes.

c) Detectamos apenas um fragmento de «tegula» e alguma cerâmica de aspecto antigo durante a batida de terreno.

As amostras foram depositadas no Museu de Conimbriga em 1983.

Foi o proprietário do terreno, Sr. António Pita, agricultor, de 73 anos, de Alcabideque, que nos indicou o «Carrascal».

d) Casal ?

14 - Nascente, Alcabideque, Condeixa-a-Velha.

a) Coordenadas Militares: 141,7; 348,7; Folha 251.

b) Exsurgência cársica da morfologia dos calcários de Alcabideque.

d) Torre de captação de águas do aqueduto de Conimbriga. 
e) J. Alarcão, R. Étienne, A. M. Alarcão, S. da Ponte, Trouvailles Diverses - Conclusions Générales, «Fouilles de Conimbriga», 7, Paris, 1979, p. 211, 213, 216, 218, 223, 236.

J. Alarcão, R. Étienne, L'Architecture, «Fouilles de Conimbriga», 1, Paris, 1977, p. 51-53, 55, 62-64, 163, 275 .

15 - Algar, Alcabideque, Condeixa-a-Velha.

a) Coordenadas Militares: 172,75; 348,5; Folha 251.

ç) Socalco da encosta de calcários liássicos do algar de Alcabideque plantada de pinhal e olival.

c) As escavações para extracção de pedra (calcário liássico) na encosta do algar de Alcabideque trouxeram à superfície escassos fragmentos de «tegula»e outras cerâmicas de construção. Surgiu igualmente uma sepultura. As amostras foram recolhidas em batida do terreno e depositadas no Museu de Conimbriga em 1983.

Fomos acompanhados ao local pelo Sr. Angelo Alves, de Alcabideque, motorista da Câmara Municipal de Condeixa.

d) Casal?

16-Vinhal, Bom Velho de Cima, Condeixa-a-Velha.

a) Coordenadas Militares: 173,2; 348,85; Folha 251.

ç) O local situa-se no Vale, junto ao Bom Velho de Cima, assente em calcários liássicos, em terrenos não irrigados; culturas variadas, circundadas de oliveiras e pinhal.

c) Achados de superfície recolhidos em batida de terreno. As amostras de «tegula», «imbrex» e tijoleira foram depositadas no Museu em 1983.

Fomos acompanhados ao local pelo Sr. Manuel Luís Simões, agricultor, de 70 anos de idade, do Bom Velho de Baixo. A propriedade pertence ao Sr. Avelino Lima de Bendafé.

d) Casal? 
17 - Reconcos, Bendafé.

d) Coordenadas Militares: 174; 348, 3; Folha 251.

ç) O local situa-se junto à estrada para o Casal Novo e os vestígios, muito dispersos e pouco abundantes, espalham-se desde a Várzea aos socalcos assentes em calcários liássicos por várias dezenas de metros.

c) Os achados superficiais foram recolhidos em batida de terreno e as amostras de «tegula», «imbrex» e tijolo de coluna deram entrada no museu em Março de 1985.

Fomos acompanhados ao local pelo Sr. Olábio Figueira de Bendafé, enfermeiro, aposentado. Um peso de tear romano está a ser reutilizado num dos teares manuais de Bendafé.

d) «Villa»?

18 - Mourêdeos, Bruscos, Vila Seca.

d) Coordenadas Militares: 176; 346,7; Folha 251.

b) Os vestígios encontram-se numa pequena várzea e na encosta de calcário virada a poente e espalham-se por cerca de cinco dezenas de metros quadrados em terrenos plantados de vinha e olival.

c) Achados superficiais recolhidos em batida de terreno. Trata-se de fragmentos de «tegula» que deram entrada no museu em 1983.

Fomos acompanhados ao local pelo Sr. Alcino Melo João, de 43 anos de idade, residente em Bruscos e motorista da Câmara Municipal de Condeixa.

d) Casal ?

19 - Choisos, Bruscos, Vila Seca.

d) Coordenadas Militares: 176,1; 346,7; Folha 251.

b) Os vestígios estão dispersos pela várzea plantada de vinha e pelos socalcos da encosta adjacente virada a poente numa extensão de mais de um hectar.

Conimbriga, 25 (1986), 53-73 
c) Achados superficiais recolhidos em batida de terreno: fragmento de mó movente, fragmentos de «tegula» e tijoleira. Deram entrada no museu em 1983.

Fomos acompanhados ao local pelo Sr. Artur Duarte Lêda, agricultor, de 75 anos de idade, residente em Alcabideque. A propriedade pertence ao Sr. Joaquim Alegre, de Bruscos.

d) «Villa»?

20 - Cascalheira, Traveira, Vila Seca.

a) Coordenadas Militares: 174,5; 346,5; Folha 251.

b) Os vestígios encontram-se em plena várzea plantada de vinha, oliveira e culturas hortícolas de inverno, entre a Ribeira de Bruscos e a encosta de calcários liássicos virada a poente, e espalham-se por algumas dezenas de metros quadrados.

c) Os achados superficiais foram recolhidos em batida de campo e depositados no museu em 1983. Trata-se de um fragmento de mó, tijolos segmentares de coluna, fragmentos de «tegula» e «imbrex» e pavimento de «opus signinum».

Fomos acompanhados ao local pelo Sr. Arsénio Maria Fernandes, guarda do Museu de Conimbriga, o qual tinha detectado os vestígios durante a caça.

d) «Villa»?

21—Lameiros, Póvoa de Pêgas, Zambujal.

a) Coordenadas Militares: 172,7; 344,8; Folha 251.

b) O local situa-se dum lado e doutro da estrada de Póvoa de Pêgas, na Várzea do Carálio Seco, onde as culturas praticadas são a vinha, pastagens, oliveira e poucos produtos hortícolas. Os vestígios espalham-se por uma área superior a um hectar.

c) Os achados casualmente feitos no decurso de trabalhos agrícolas foram depositados no museu em 1964. Trata-se 
de dois sestércios de Trajano e Adriano (cf. Isabel Pereira, Miguel Pessoa, Moedas Romanas de Condeixa. Achados dispersos, «Filatelia/Numismática», 5, 1981, p. 28-30), cujo estado de conservação não permite uma classificação cronológica precisa, fragmentos de mosaico polícromo, anel de bronze com mesa,fragmento de almofariz de mármore, fragmentos diversos de cerâmica comum e de telhas.

Fomos acompanhados ao local pelo Sr. Doutor Jorge Alarcão, em Outubro de 1984.

A propriedade pertence ao Sr. Diamantino Jorge Mendes, de Fonte Coberta, Zambujal, Condeixa.

d) «Villa».

e) Mário SAA, as grandes vias da Lusitânia. O Itinerário de Antonino Pio, 3, Lisboa, 1960, p. 244-246.

22 - Covâo da Póvoa, Zambujal.

a) Coordenadas Militares: 172,1; 342,6; Folha 251.

b) $\mathrm{O}$ local situa-se à beira da estrada para a Serra de Janeanes, numa encosta de terrenos calcários margosos do Liássico (Secundário), virada a nascente para o Vale do Carálio Seco, em frente à povoação do Zambujal. A encosta encontra-se cortada por vários arrifes paralalelos à extensão desta e que prolêm do afloramento das bancadas mais calcárias. Alguns vales encaixados cortam a encosta no sentido poente/nascente. Nas zonas mais margosas (entre os arrifes) pratica-se uma agricultura de sequeiro com pastagens, pouco cereal e oliveira. As várzeas do Carálio Seco, estreitas, permitem algumas culturas hortícolas e vinha, embora com dificuldades de água. As bancadas calcárias permitem o corte de pequenos blocos apropriados para a construção e pavimentação de passeios.

c) A quantidade de blocos paralelepipédicos que se amontoam nos muros de separação de propriedades sugere trabalho humano de desmonte e aperfeiçoamento desses blocos para fins de construção. 

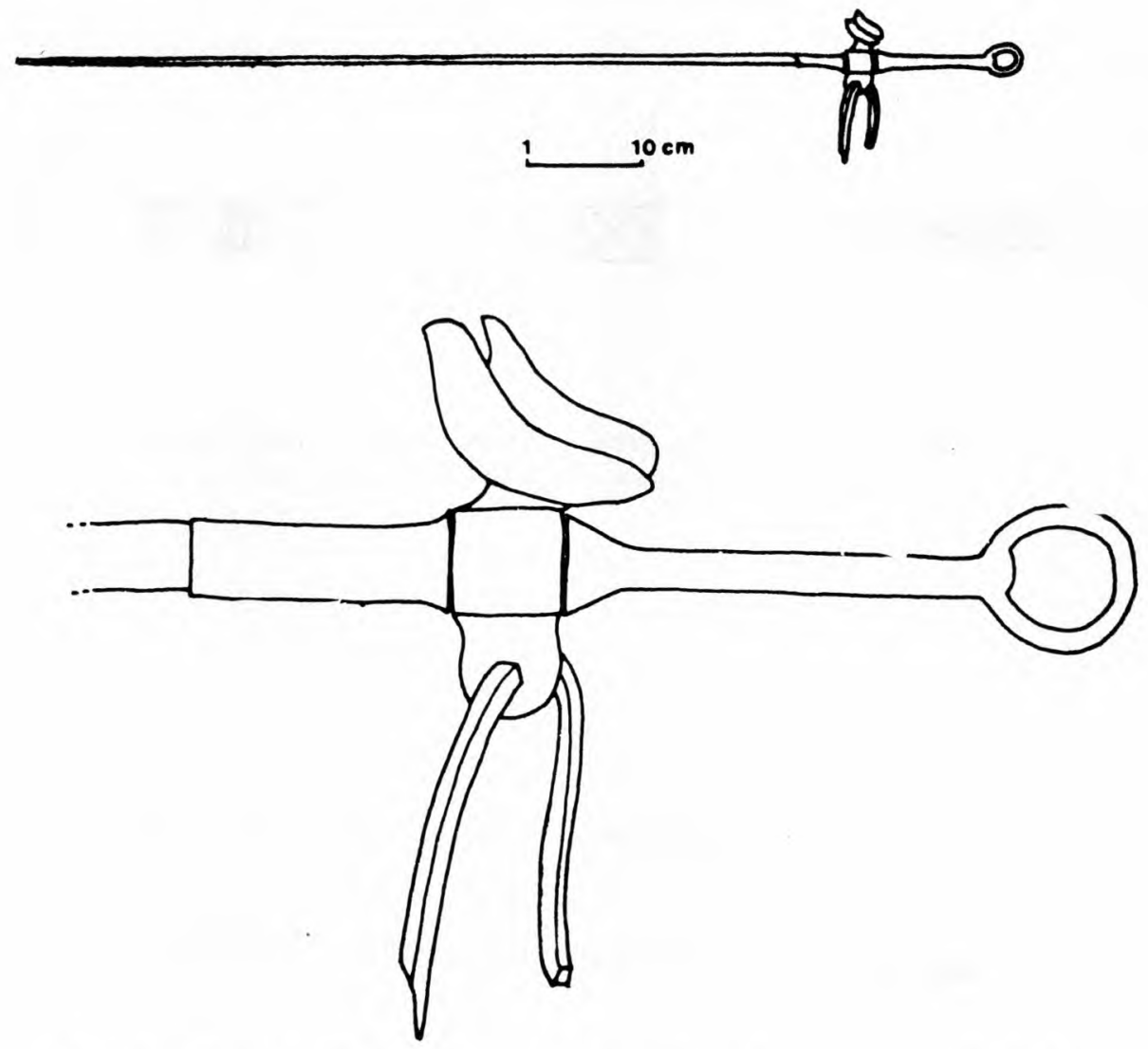

Fıg. 1 - O espeto de Alvaiázere que apresenta as duas aves na articulaçào (baseado em Coffyn, 1985). 


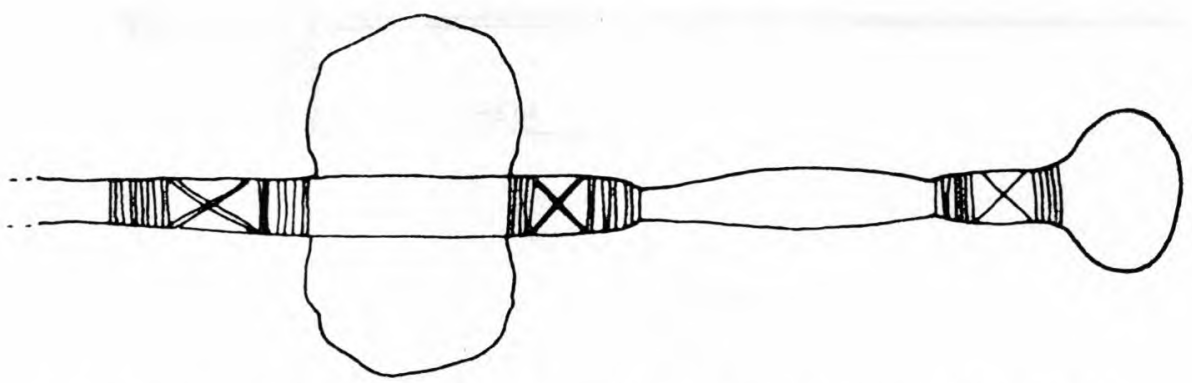

Fig. 2 - Espeto tipo Sudoeste, grupo Portuguès. (Col. Museu Nacional de Arqueologia e Etnologia, in Estácio da Veiga, 1891).
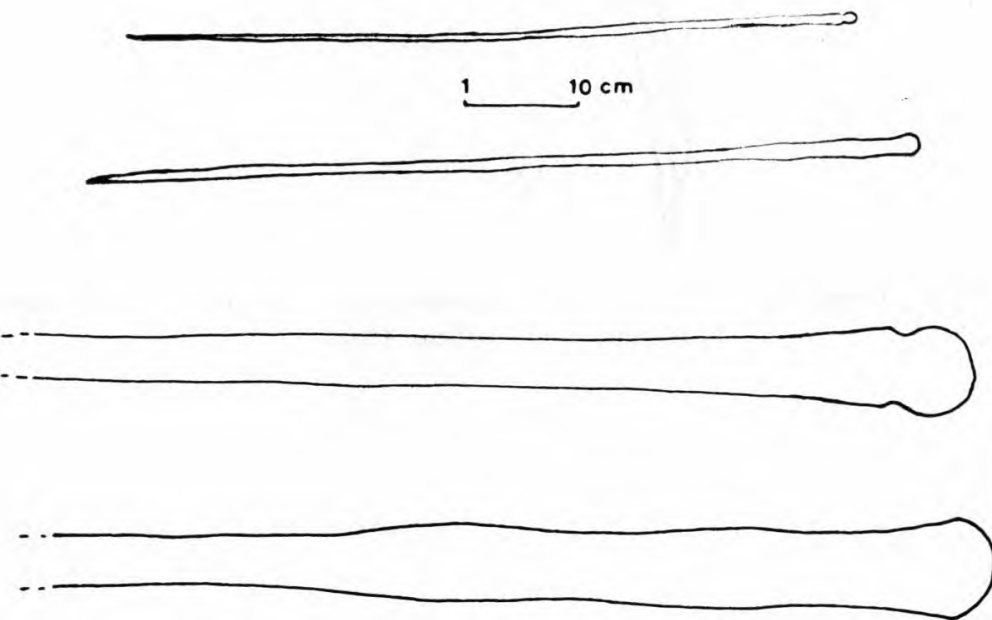

Fig. 3 - Espetos tipo Sudoeste, grupo do Guadalquivir (exemplares de Moura e Sevilha, baseado em Almagro Gorbea, 1974, e Fernandez Gomez, 1982). 
Os vestígios encontram-se localizados num patamar sobranceiro a uma zona de forte pendor para Nascente, o que lhe dá uma situação altaneira perante o vale do Carálio Seco.

Os vestígios detectados (telhas, tijoleiras e cerâmica comum calcítica) estendem-se por várias centenas de metros quadrados dum lado e doutro da estrada de Janeanes.

Estes achados superficiais recolhidos em batida de terreno deram entrada no museu em 1983.

Fomos acompanhados ao local pelo Sr. José Coelho, do Zambujal. A pedreira e terrenos anexos pertencem ao Sr. Abílio Carvalho, de Zambujal.

d) Casal ?

23 - Algar, Vale de Janes, Ega.

a) Coordenadas Militares: 166,2; 344,2; Folha 250.

b) Terreno encostado à Estrada Nacional n. ${ }^{\circ}$, em pequeno campo de oliveiras e pasto sobrejacente a calcários carsificados do dogger.

c) Achados superficiais recolhidos em batida de terreno.

Embora a cerâmica recolhida seja semelhante à cerâmica comum romana, nenhum exemplar nos permite dizer tratar-se categoricamente de cerâmica romana.

Fomos acompanhados ao local pelo Sr. Arménio Silva, restaurador de móveis em Condeixa e residente em Vale de Janes.

d) Casal ?

24 - Moroiços, Ordem, Rabaçal, Penela.

a) Coordenadas Militares: 172,3; 341,1; Folha 251.

Zona limite entre os concelhos de Condeixa e Penela.

b) O local situa-se numa das plataformas de rebordos alcantilados na base da encosta de Maria Pares (Jurássio Infe-

Conimbriga, 25 (1986), 53-73 
rior) percorrida por arrifes na direcção norte/sul. Trata-se de terras argilosas de semeadura e olival.

c) $\mathrm{Na}$ sequência do inquérito lançado pelo Instituto de Arqueologia da Faculdade de Letras de Coimbra, em 1956, fora dada a informação da existência de vestígios de mosaicos romanos na «Aldeia», Ordem, Rabaçal. A obra de Jorge Alarcão, Portugal Romano, editada em 1973, assinala-o (Est. V).

O sítio é localizado em 1979 e, em 1984, são realizadas as primeiras sondagens e efectuadas, no ano seguinte, as primeiras escavações.

Os materiais estão depositados no museu.

d) «Villa».

e) M. Pessoa, S. da Ponte, Escavações no Rabaçal, «Arqueologia», 10, Porto, 1984, p. 113-116.

Idem, Moroiços, Ordem, Rabaçal, Penela, «Informação Arqueológica», 6, Lisboa, 1986, p. 39.

Miguel Pessoa, Lino Rodrigo, $A$ Exposição "Em Defesa da Memória de Todos» e os Fundamentos para a criação de um Ecomuseu em. Condeixa, Figueira da Foz, 1985 , p. 26 e 29.

\section{Considerações}

A nossa análise abordará dois aspectos ligados ao desenvolvimento introduzido pela civilização romana neste território: a rede viária e o povoamento.

A circulação viária foi certamente, nalguns casos, uma forte razão de fixação. Não se detectaram por enquanto vestígios das estradas e ramais romanos para além das estradas de Conimbriga $\left(^{2}\right)$.

O trajecto de «Sellium» (Tomar) para esta cidade estava integrado no traçado da grande via que ligava «Olisipo» a «Bracara Augusta». Ainda há poucas dezenas de anos, o trajecto por Tomar constituía o percurso obrigatório para quem demandava atra- ${ }^{*}$ )

(*) O tipo de lajeamento assinalado em «Vale Montum», Alfafar, Penela merece, apesar de tudo, referência. Afigura-se-nos difícil definir a sua época. 
vessar o País. Também os mapas e roteiros dos sécs. xviI, xvm e xix fazem referência à continuidade da passagem da via por locais bem próximos, como sejam Ansião, Rabaçal, Fonte Coberta e Alcabideque ( $\left.{ }^{3}\right)$.

Os vestígios romanos localizados nesta direcção comprovam a antiguidade do trajecto (ver Carta Arqueológica n. ${ }^{\text {s }} 21,22$ e 24) (*).

Qual seria o trajecto para Norte? Passaria pelos locais assinalados em 11, 10 e 13, na direcção do acampamento romano de Antanhol ( ${ }^{5}$ ) e villa romana da Palheira? (6). Ou a Nascente da Serra de Avessada e depois na direcção de Venda* do Cego e do acampamento romano de Antanhol? Qual o percurso para alcançar a margem esquerda em frente a «Aeminium»? $\left({ }^{7}\right)$.

(3) Cf. Angel Sanches rivero e Angela M. de Sanches rivero, «Viaje de Cosme de Medicis por España y Portugal (1668-1669)», Madrid, 1933; «Mappa ou Carta Geographica dos Reinos de Portugal e Algarve», por J. Jefferys, Geographo de Sua Magestade Britannica, Londres, 1790 (Róteiro do Museu de Óbidos, 1983, n. ${ }^{\circ}$ 96); «Carta Militar das principais estradas de Portugal», desenhada por Lourenço Homem e gravada por «Romão Eloy de Almeida, Lisboa, 1808». (Roteiro do Museu de Óbidos, 1983, n. ${ }^{\circ}$ 97).

${ }^{4}$ ) A cerca de três quilómetros da povoação de Rabaçal, na direcção de Ansião, foi recentemente assinalado um local de nome «Barbealho» (terra de semeadura e olival), onde se detectam facilmente à superfície vestígios de «tegula», «imbrex» e cerâmica comum. As amostras recolhidas em 1985 foram depositadas no museu.

Perto deste local, em frente à povoação dos Tamazinhos (Carta Militar 1:25 000, n. ${ }^{\circ} 263$ ) foi descoberto um miliário do imperador Décio (250 d.C.). Deu entrada no Museu de Conimbriga em 1983.

$\left.{ }^{5}\right)$ Cf. Faculdade de Letras da Universidade de Coimbra, Subsídios para o estudo do acampamento romano de Antanhol, «Biblos», 25, Coimbra, 1959 , p. 599-652.

Cf. Instituto de Arqueologia da Faculdade de Letras da Universidade de Coimbra, Acampamento romano de Antanhol, «Conimbriga», 2-3, Coimbra, 1960/1961, p. 12.

(6) Cf. Vergilio Corre ia, Notas de Arqueologia e Etnografia do Concelho de Coimbra, «Biblos», 16/1, 1940, p. 107 e 108 .

Maria Amélia Horta Pereir a, Situla com inscrição encontrada em S. Silvestre, Palheira, Assafarge, "Actas do 2. Congresso Nacional de Arqueologia», 2, Coimbra, 1971, p. 365-369.

(7) Cf. J. Alarcĩo, As origens de Coimbra, «Actas das I Jornadas do Grupo de Arqueologia e Arte do Centro», Coimbra, 1979, p. 23-40. 
Para Sudoeste, a saída pela «Ponte Romana do Rio dos Mouros» (ver Carta Arqueológica, n. ${ }^{\circ}$ 7) sugere-nos uma ligação a «Roda», Redinha, Pombal $\left({ }^{*} \mathrm{~S} .{ }^{*} * 8\right)$, no ramal que serviria "Gollipo» (S. Sebastião do Freixo), Batalha e «Eburobritium» (Évora de Alcobaça ou Amoreira de Óbidos) $\left({ }^{9}\right)$.

E a ligação viária para Oeste? Far-se-ia na direcção de Soure? $\left(10^{*}\right)$.

E para Noroeste? A proliferação de vestígios nesta zona («villae» e casais) leva-nos a aceitar a hipótese da existência de um ramal importante. Este seguiria mais em direcção a Norte ou derivaria mais para Noroeste na direcção de Formoselha $\left(^{n}\right)$, Montemor-o-Velho (12) e Santa Olaia $\left({ }^{13}\right)$.

Importa também ligar o desenvolvimento introduzido pela civilização romana com a presença de unidades agrárias onde trabalhavam os escravos e os homens livres, elas próprias com diferenças que nos parecem detectáveis não só pela sua localização

(8) Cf. A. Santos Rocна, Estação luso-romana de Roda, «Boletim da Sociedade Arqueológica Santos Rocha», n. ${ }^{\circ}$ 9, 1909, p. 249-250.

Idem, O Museu Municipal da Figueira da Foz, Catálogo Geral, Additamento i. $.^{\circ}, 1906-1907$, Figueira, 1909, n. ${ }^{\text {os }} 8463$ a 8465.

$\left.{ }^{9}\right)$ Cf. J. Ala rc ã o, Portugal Romano, Lisboa, 1973, fig. 6 e 14.

(10) Foram detectados vestígios romanos na Cramoa, Alto da Madalena, Soure.

Cf. A. Luís S. Henriques SEco, Memória Histórica e Corographica de diversos Concelhos do Distrito de Coimbra, Coimbra, 1983.

A. Santos Conce Içã o, Soure, Coimbra, 1942, p. 12.

Há notícia incerta da existência de mosaicos romanos na Quinta de

S. Tomé, em Vila Nova de Anços.

(u) Cf. A. Santos Roc H A, Estação romana de Formoselha, «Portugalia», 1-2, Porto, 1900, p. 344.

(12) Cf. A. Santos Rocн a, Necrópole luso-romana da Senhora do Desterro, Montemor-o-Velho, «Portugália», 1, Porto, 1899, 1903, p. 596-598.

Idem, Catálogo do Museu Santos Rocha, Figueira da Foz, 1905, n. ${ }^{\circ} 4225$ (mosaico).

Ala RCão, Portugal Romano, p. 196.

Jean Gérard Gorges, Les villas hispano-romaines (Portugal), Bordeaux, 1978, p. 405.

(13) Cf. A. Santos Rocн A, Memorias e explorações arqueológicas, 2, Estações pré-romanas da Idade do Ferro nas vizinhanças da Figueira, Coimbra, 1971. 
mas também pela diversidade do espólio que apresentam (14). A distribuição dos sítios arqueológicos atesta uma grande densidade populacional, da qual decorre a presença de pequenas e médias propriedades, de culturas intensivas e variadas $\left({ }^{15}\right)$.

Os vestígios de pavimento de mosaico apresentam-se em sítios privilegiados pela natureza dos terrenos que o homem disciplinou $\left(^{16}\right)$. Estamos certamente na presença de «villae» nos n.os 6, 11, 21 e 24 da Carta Arqueológica apresentada. O mosaico é usado por vários autores como um elemento identificador das «villae» romanas. Trata-se de ura produto que significa riqueza, ostentação e, do ponto de vista económico, o mosaico rural sugere o regresso da riqueza produzida $\left({ }^{17}\right)$.

Apesar de não detectarmos vestígios de mosaico nos n.os 2, $5,9,10,16,17,18$ e 20, a abundância de materiais e a sua localização levam-nos a pôr a hipótese de estarmos perante mais «villae» luso-romanas $\left({ }^{18}\right)$. Distam, em média, $3 \mathrm{~km}$ umas das outras.

(14) Os aglomerados natural e estrategicamente defendidos - como Conimbriga - são sempre acompanhados por uma comunidade instalada a pouca distância.

Cf. António García Bellido, Problemas sociales del urbanismo en el area mediterranea durante la Edad Antigua, «13. ${ }^{\circ}$ Congreso Internacional de Ciências Históricas», Moscovo, 1970, p. 2.

(15) Cf. «Esboço da Carta Geral de Ordenamento Agrário, Capacidade e Uso dos Solos. Serviço de Reconhecimento e Ordenamento Agrário», n. ${ }^{\text {os }} 250,251,240,241$.

«Carta agrícola e florestal de Portugal - Serviço de Reconhecimento e Ordenamento Agrário», n.os 250, 251, 240, 241.

(16) Cf. José L. Ona Gonzalez, El poblamiento rural de época romana en una zona de la ribera de Navarra, in "Arqueologia Espacial», 5, Teruel, 1984, p. 84.

(17) Cf. Jorge AlarCão, os problemas da origem e da sobrevivência das «villae» romanas do Norte do País, «Actas do Seminário de Arqueologia do Noroeste Peninsular», 3, Guimarães, 1980, p. 171-179.

Enrique Cerrillo Martin de Cáceres, José Maria Fernández Corrales, Un ejemplo de relación campo-ciudad. Ija distribution espacial de los mosaicos romanos en Lusitania, «Norba», 2, Cáceres, 1981, p. 157.

(18) «...A villa romana é urna exploração pré-capitalista: o seu proprietário pretende produzir muito mais do que aquilo que, com sua família e criados, consome. A villa não pode portanto existir sem mercados consumidores, e esses mercados são, na época romana, a cidade e o exército...», Alarcão, Portugal Romano, p. 104.

Conimbriga, 25 (1986), 53-73 
Trata-se de zonas próximas de nascentes e cursos de água permanente $\left({ }^{19}\right)$, próprias para desenvolver várias culturas no ano $\left({ }^{20}\right)$, plantação de oliveiras, vinhas, árvores de fruto e criação de gado (21). A localização prudente das habitações não as deixa vulneráveis aos precalços das cheias. Os cursos de água e as zonas húmidas dos paúis (Azenha, Anobra e Arzila) (22) proporcionariam uma ligação fluvial até à costa e a fácil captura de espécies, tanto pela caça como pela pescai ${ }^{23}$ ), indispensável para a vida de toda a população. As espécies vegetais, como sejam o bunho, o junção ${ }^{24}$, o vime, caules de cereais, cana, outros filamentos e madeiras eram naturalmente utilizados para o fabrico de um diversificado número de objectos de artesanato de uso quotidiano. Também os montes reuniriam boas condições para a gestação das espécies selvagens nas várias épocas venatorias e os seus pastos alimentariam muitos rebanhos cuja lã era indispensável para o fabrico de tecidos $(25)$.

Para a feitura de variada utensilagem, para a construção das habitações e outras estruturas, era indispensável uma matéria-

(19) J. Alarcĩo, R. Étienne, J. Claude Golvin, Joseph Schreyeck, Raymond Monturet, VArchitecture, (Fouilles de Conimbriga, I), Paris, 1977, p. 52.

(20) $\mathrm{y}_{\mathrm{er}}$ "Alfaia Agrícola» in J. Alarcão et alii, Céramiques diverses et verres (Fouilles de Conimbriga, 6), Paris, 1976, p. 39-45.

(21) Estrabão salienta a riqueza da Lusitânia em termos da produção de gado e seus produtos (lãs, leite, carne e peles) que eram trocados por cerámica, sal e objectos de bronze.

Cf. Julio Esteban Ortega, El comercio de exportación en Lusitania a través de las fuentes, «Vettonia», Cáceres, 1983, p. 32.

(22) Cf. Francisco Ferrand de Almeida et alii, Aspectos faunísticos, florísticos, geológicos e geográficos do Paúl de Arzila, "Ciências Biológicas, Ecológicas, Syst. (Portugal)», 5, Coimbra, 1983, p. 43-78.

(23) Cf. J. Ala Rcão et alii, Trouvailles diverses, conclusions genérales, (.Fouilles de Conimbriga, 7), Paris, 1979, p. 45.

(24) Cf. opúsculo da exposição monográfica «Esteiras de Arzila», Torre de Anto, Casa do Artesanato da Região de Coimbra, 1984.

(25) Cfr. «Instrumentos de tecelagem», em Al a RC Ã o, Trouvailles diverses. Conclusions gênèrales, (Fouilles de Conimbriga, 7», Paris, 1979, p. 52-80.,

Adília Alarcão, Sálete da Ponte, O tempereiro e a antiguidade do tear horizontal de pedais, «Conimbriga», 21, Coimbra, 1982, p. 165-168. 
-prima facilmente disponível. Não faltavam a madeira e os barreiros ${ }^{(26)}$. Era possível construir em taipa, e o calcário de vários tipos permitia uma utilização variada que ia desde o lajeamento das estradas, passando pelo trabalho de cantaria, até ao seu cozimento para a obtenção da cal (27). Na zona de Alencarce, entre Condeixa e Soure, existem jazidas de grés donde os Romanos poderiam ter extraído mós $\left({ }^{28}\right)$.

Os restantes locais habitados, com os n. ${ }^{\text {s }} 1,3,4,13,15$, $18,22,23$, serão pequenos casais, tanto pela exiguidade do espólio recolhido (apenas «tegulae»e «imbrices») como pela proximidade de locais identificados como «villae», e também pelas aparentes fracas condições naturais dos locais onde foram implantadas as habitações.

Poderá identificar-se alguns destes sítios com o «vicus Baedorus», de que nos fala a inscrição de Conimbriga registada por Hübner ? (29).

Só os futuros trabalhos de intervenção no terreno poderão dar esta e outras informações sobre a vida na área rural envolvente da cidade de Conimbriga.

(26) «Os barreiros abundantes na zona de Anobra, a $6 \mathrm{~km}$ para noroeste de Conimbriga, podem ter servido para a produção de cerâmica que serviu nas lides domésticas e artesanais». Cf. A. Alarcão, Colecções do Museu Monográfico de Conimbriga. Catálogo, Coimbra, 1984, p. 26.

${ }^{(27)}$ Cf. mapa geológico dos arredores de Conimbriga, in J. AlarCão et alii, VArchitecture (Fouilles de Conimbriga, 7), Paris, 1977, P1. 2.

(28) Cf. Nelson Borges, mós manuais de Conimbriga, «Conimbriga», 17, Coimbra, 1978, p. 131.

${ }^{29}$ ) Conhece-se o texto mas a inscrição desapareceu (NETO VALERIYS . AVIT M . TVRRANIVS . SVLPICI DE VICO BAEDORO GENTIS . PINTON). Cf. E. Hübner, Corpus inscriptionum latinarum, II, Berlim, 1968, n. ${ }^{\circ} 365$.

Cf. R. Étienne, G. Fabre, P. et M. LévêQue, Épigraphie et sculpture, [Fouilles de Conimbriga, 2), Paris, 1976, n. ${ }^{\circ} 15$, p. 35. 
(Página deixada propositadamente em branco) 
EST. I
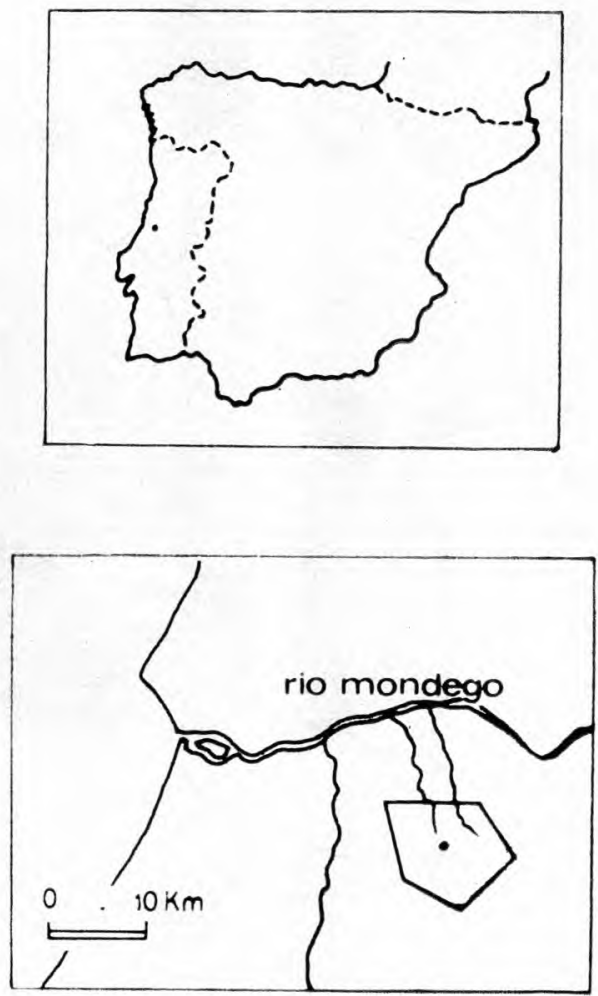

- Situação geográfica da zona estudada, escala 11000000.

- CONIMBRIGA 
EST. II

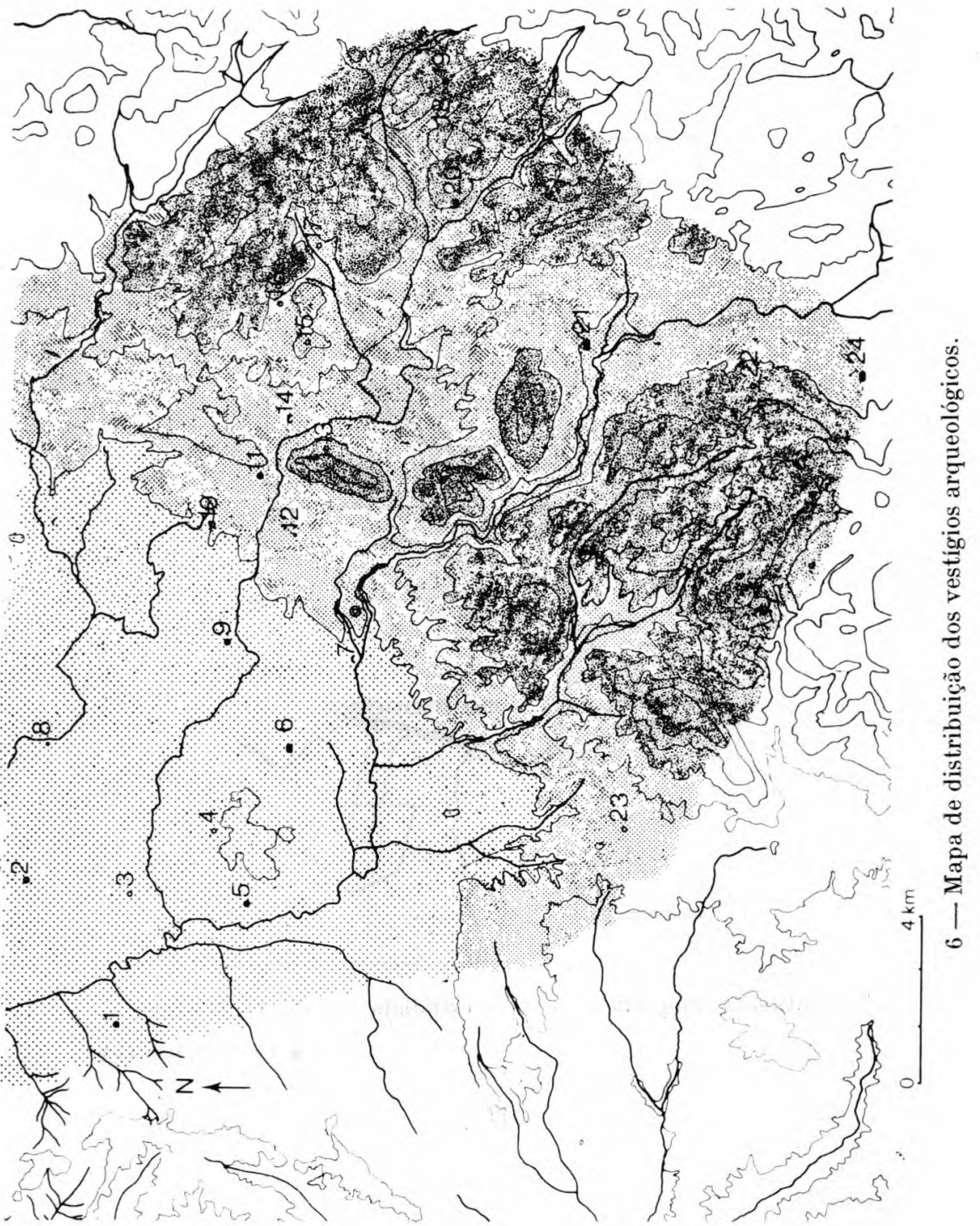




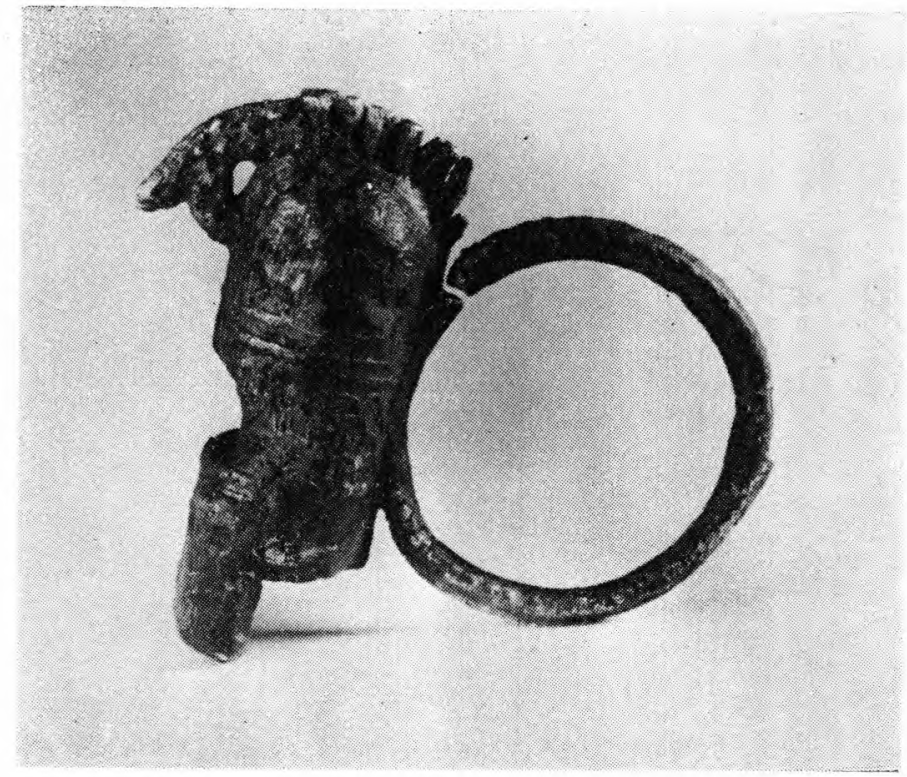

1 - Anel romano com apito militar (Valada, Condeixa-a-Velha). Diâmetro $20 \mathrm{~mm}$; altura do apito $28 \mathrm{~mm}$, espessura $9 \mathrm{~mm}$.
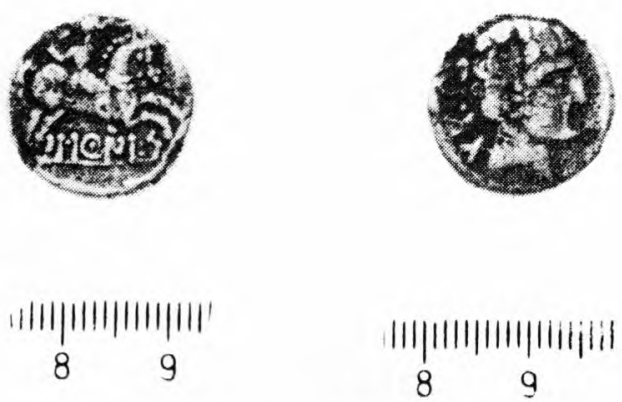

2-Moeda ibero-romana de Casével (Ega). Denário (prata). Anverso: cabeça, à dir., de Ares (Marte) ibérico; atrás, $\hat{X} \mathrm{MXX}$; reverso: g’uerreiro a cavalo, à direita, segurando as rédeas com a mão esquerda e a espada com a direita. Por baixo do cavalo, II.ICNI:S (LASCUNIS ou BASCUNIS). Cironologia: 105-80/72 a.C. Bibliografia: GU AD AN, Numismática Ibérica e Ibero romana, Madrid, 1969, n. ${ }^{\circ} 362$, p. 203. 
Est. IV

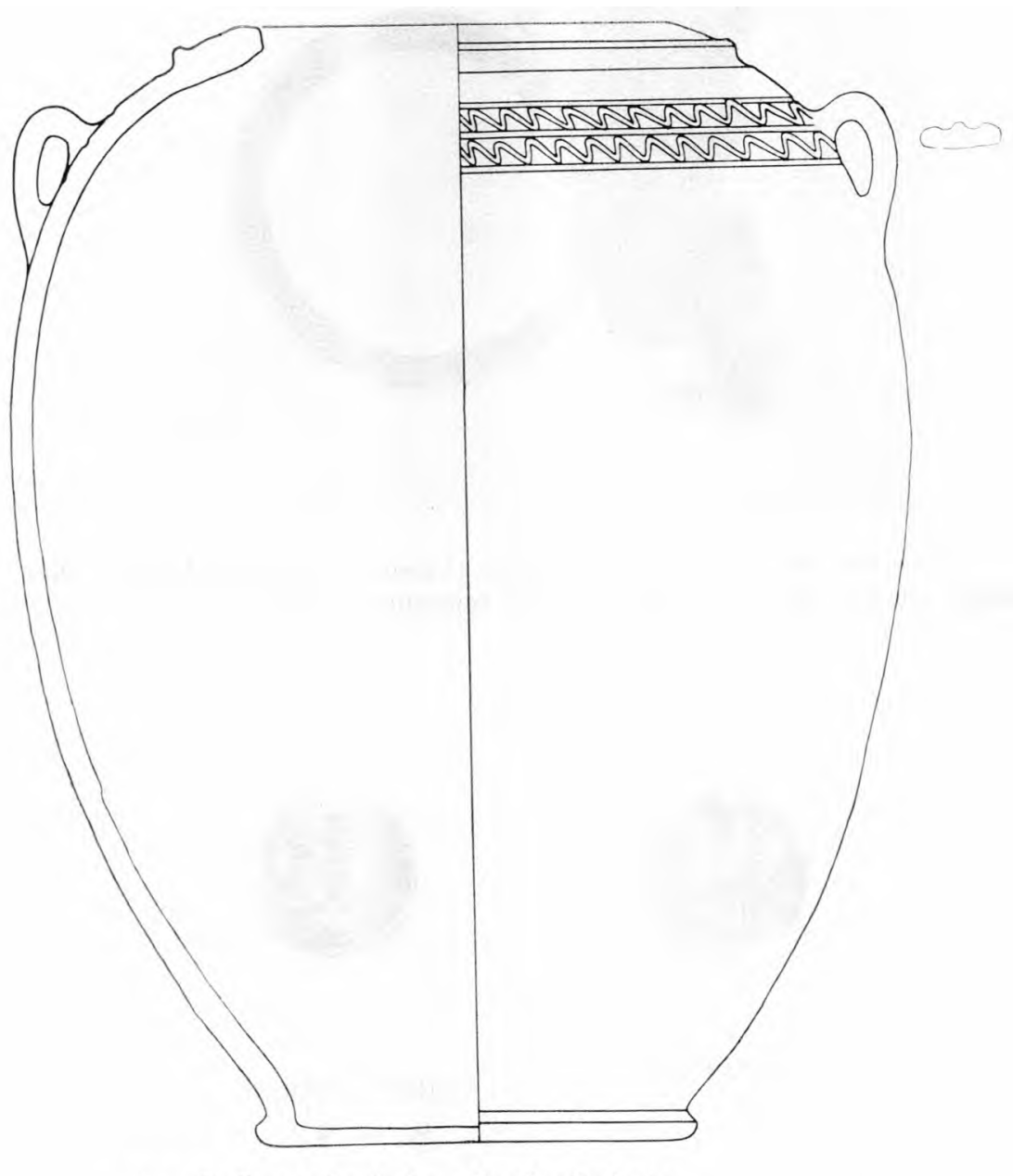

3 - «Dolium» de Areias, Venda da Luísa.

Esc. $1: 8$ 


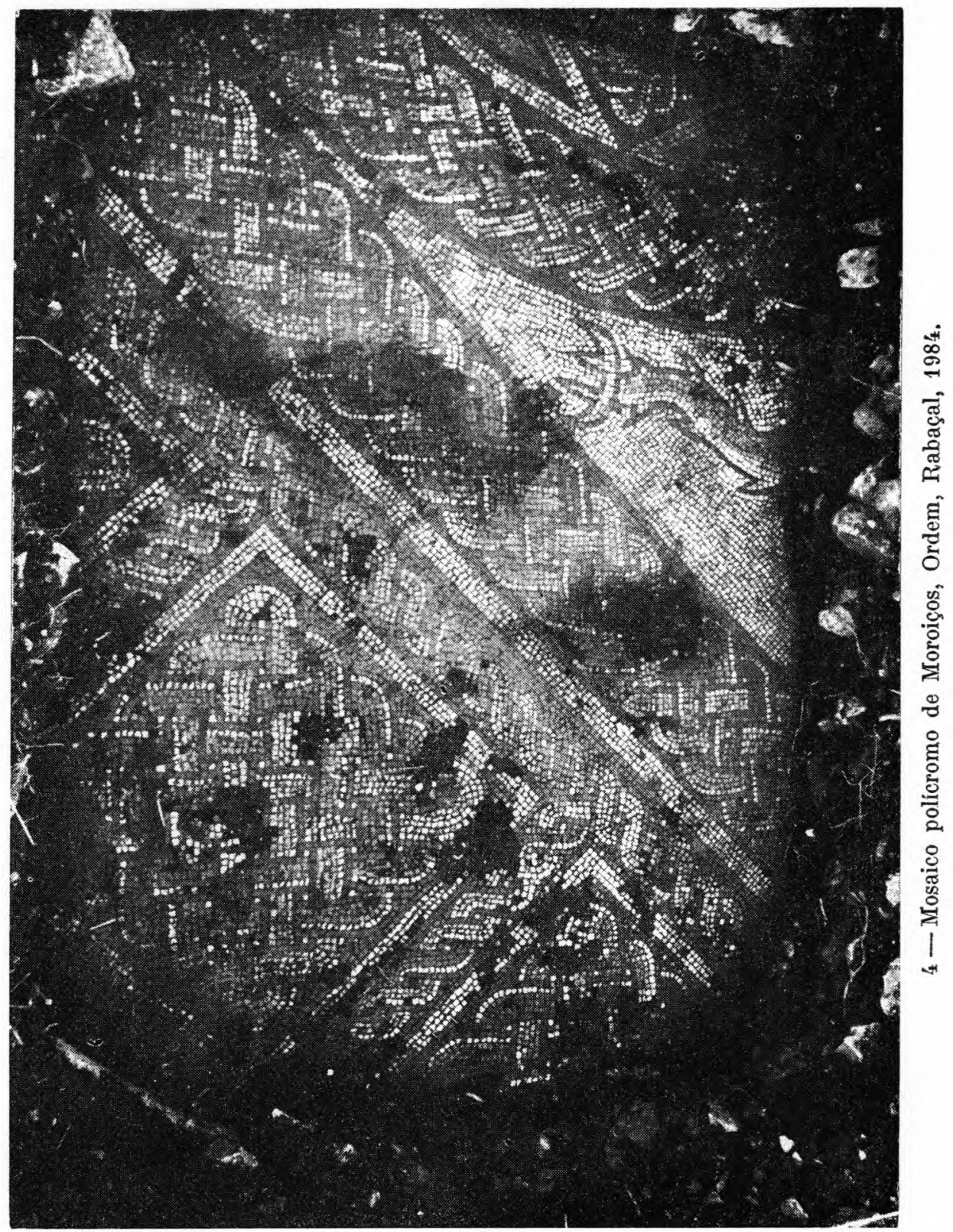

